\title{
Options to Evaluate The Effects of a Change in the Shape of the Flow Cross-Section of a Ball Valve on Its Flow Control Properties
}

\author{
Peter Lukáč ${ }^{*}$, Peter Horbaj', Jarmila Sedláková ${ }^{2}$ \\ ${ }^{1}$ Technical university of Košice, Faculty of Mechanical Engineering, Department of Power Engineering, Vysokoškolská 4, 04200 Košice, SR \\ 2 jarmila.sedlakova.ing@gmail.com
}

\section{BIOGRAPHICAL NOTES}

Ing. Peter Lukáč, PhD., is a graduate of Thermal Power Engineering from Faculty of Metallurgy, Technical University of Košice. He currently works as a senior assistant professor at Department of Power Engineering, Faculty of Mechanical Engineering of TU of Košice. He takes part in solving research assignments, grants and projects at the department and the university. His research interest includes heat supply, compressors, pumps, combustion devices, cooling equipment and heat pumps. He is an author of over 50 original manuscripts published in local and international journals; conference papers and 4 university textbooks. He is a member of the Editorial Board of Gas-WaterHeating-Air-conditioning Journal.

prof. Ing. Peter Horbaj, CSc., is a professor at Department of Power Engineering, Faculty of Mechanical Engineering, Technical University of Košice. He is an author and coauthor of 7 textbooks, co-author of 1 patent and an author/co-author of 305 papers published in various local and international journals. He has presented results of his work on various international conferences. His research and project assignments focus on energy utilization of waste treatment, impulse burners, biogas stations, utilization of wood chips. He has been awarded several prizes.

Ing. Jarmila Sedláková, is a graduate of Faculty of Mechanical Engineering, Technical University of Košice. She worked as a senior assistant profesor at Department of Mechanics and Parts of Machine and Department of Technical Devices Design, Faculty of Manufacturing Technologies with a seat in Prešov of TU Košice and she worked as a mechanical designer at Department of Machine Design (robots, manipulators and control valves) in ZPA Prešov. She was taken part in solving research assignments, grants and projects at the departments at the university. She is autor and co-autor of academic text books and conference papers.

\section{KEY WORDS}

Ball valve, Valve characteristic, Flow coefficient, Pressure differential, Flow simulation.

\section{ABSTRACT}

This article examines the possibility of the application of numerical methods in the determination of valve characteristics. Using a prototype ball valve with an elliptical closing element as an example, comparisons were made between the measured and numerically simulated flow rate and pressure differential values of the valve. This method can be applied in the process of designing the control characteristics of valves. 


\section{INTRODUCTION}

Valves are devices designed to control the flow of a fluid depending on the specific conditions of the piping system concerned. To be able to perform this function, valves must have appropriate properties corresponding to their design and method of actuation, if any. It is possible to use ball valves to control the flow in piping systems, and they are particularly suitable for various heat-carrying systems. One of the advantages of ball control valves is their obvious equal percentage characteristic.

The properties that a ball valve needs to have to be able to efficiently perform its control function must be enabled primarily by the design of the fitting and its throttling system, and the control actuation characteristics. Another necessary precondition is an appropriate design of the valve.

The parameters of any control fitting include its nominal size (DN), nominal pressure (PN), and the maximum operating temperature of the fluid, determined by the manufacturer, to which the fitting may be exposed during operation. Another important indication is the rated flow coefficient which is a typical parameter of a control fitting. Its size determines the characteristic flow rate of the fitting under accurately defined conditions and at the rated $(100 \%)$ stoke. It allows calculation of the flow rate of the operating media, or the local pressure loss in the fitting under general operating conditions. One commonly used coefficient is Kvs.

Flow rate characteristic, on the other hand, describes the function between the instantaneous flow coefficient and the position of the throttling fitting. Valves are most often made with either linear or equal percentage flow rate characteristics. Control (turndown) ratio is the ratio of the maximum flow coefficient to the minimum flow coefficient. In practice, it is the ratio of the maximum flow to the minimum controllable flow. The least or minimum controllable flow rate is always higher than zero. Further characteristic parameters may include the maximum leakage when closed. For control valves, this value is normally described by the maximum flow percentage (Kvs).

\subsection{Flow coefficient}

Flow coefficient, Kv indicates the volume of water in $\left(m^{3} \cdot h^{-1}\right)$ which flows through the control valve at the referenced flow conditions and the specified stroke (pressure differential of 1 bar between the defined off-take points before and after the fitting, water temperature of $15^{\circ} \mathrm{C}$, fully developed turbulent flow, sufficient static pressure that excludes the possibility of cavitation at the prevailing conditions).

The definition formula is as follows [1]:

$$
K v=\frac{1}{100} \cdot Q \cdot \sqrt{\frac{\rho_{1}}{\Delta p}}(-)
$$

where: $Q$ - is volume flow rate $\left(\mathrm{m}^{3} \cdot \mathrm{h}^{-1}\right), \rho$ - is density $\left(\mathrm{kg} \cdot \mathrm{m}^{-3}\right), \Delta p$ - is pressure loss of the fitting $(\mathrm{Pa})$.

If the fluid is water, the flow rate may be calculated by means of a simplified continual proportion method using the square root of the hydraulic gradient. By adding density of $1000 \mathrm{~kg} \cdot \mathrm{m}^{-3}$ and the determined pressure differential in bars, the Kv formula will be as follows [1]:

$$
K v=\frac{Q}{\sqrt{\Delta p}}(-)
$$

When $K_{v}$ is known, this simple equation allows us to calculate the flow rate values as well as the pressure loss using the following formulae from which the actual pressure loss for a known flow rate can be calculated as follows:

$$
\Delta p=\left(\frac{Q}{K v}\right)^{2}(\text { bar })
$$

and if the pressure loss is known, the actual flow rate can be calculated as follows:

$$
Q=K v \cdot \sqrt{\Delta p}\left(m^{3} \cdot h^{-1}\right)
$$

\subsection{Rated flow coefficient}

The flow rate coefficient $(K v)$ is the instantaneous flow rate coefficient value of a control valve which indicates the positions of the throttling element whose change determines the required change in the flow rate or pressure. The rated flow rate coefficient (Kvs) is the value of the flow rate coefficient of a mass-produced control fitting when fully opened.

\subsection{Flow rate characteristic}

Flow rate characteristic describes the flow coefficient as a function of the position of the closing element of the control device [1].

$$
K v=K v(H)(-)
$$


Relative flow rate coefficient is the ratio of the instantaneous flow coefficient, $K v$ to the rated flow coefficient, Kvs indicated by the manufacturer [1].

$\Phi=\frac{K v}{K v s}(-)$

Relative flow rate is the relative flow coefficient in the function of the relative position of the closing element of the control device, $h$, which is determined by the ratio of the instantaneous stroke of the fitting, $\boldsymbol{H}$ to its rated stroke, $\boldsymbol{H}_{100}$ [1].

$$
\Phi=\Phi(h)(-)
$$

Basic flow rate characteristics are the following: Linear flow rate characteristic is a characteristic with which the same increments in the relative stroke, $h$ induce the same increments in the relative flow coefficient, $\Phi$.

Equal percentage flow rate characteristic is a characteristic with which the same increments in the relative stroke, $h$ induce the same percentage of increments in the relative flow coefficient, $\Phi$.

Parabolic flow rate characteristic has less common use. Its behaviour is a compromise between the linear and equal percentage flow rate characteristics. Its advantage lies in that it combines the properties of the two in situations when control is needed at a number of states that are not much distant from each other and control using the equal percentage characteristics would be too steep in the area of the maximum and, on the contrary, the excessive steepness of the linear curve would not be appropriate in the area of the minimum.

\section{Measurements in a Test Circuit and Simulation in Ansys_CFX Software}

The measurements with the ball valve prototype were performed in the laboratory of the Department of Power Engineering, Faculty of Mechanical Engineering of the Technical University of Košice. Measurements were done first for a conventional circular shape of the outlet orifice cross-section, and then for an elliptical cross-section. The ball valve with which the pressure and flow rate conditions were examined is shown in Figure 1.

\subsection{Measurements}

The measurements were made using a test circuit of the fluid flow testing laboratory. The flow rates were measured by means of a GE Transport PT878GC ultrasonic flow meter. Discharge ball valves with Nivopress NZP 010 pressure transmitters were installed both before and after the test valve. The range of the transmitter provided before the valve was $1 \mathrm{MPa}$ and that of the transmitted past the test valve was $0.5 \mathrm{MPa}$. The flow meter setting temperatures were monitored by a TK 122-1 6e temperature sensor with an Almemo MA 2390-8 data logger. The logging of the measured values was done in LabVIEW software .

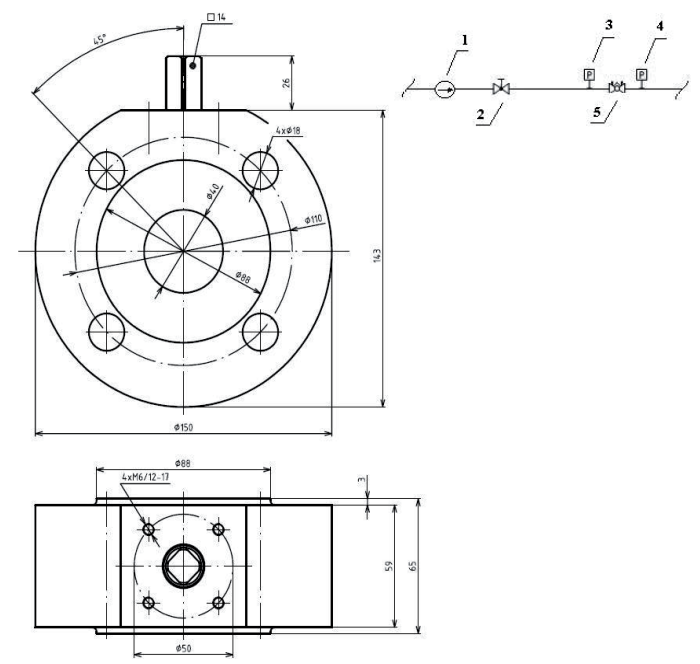

Fig. 1: DN 40 ball valve and schematic diagram ( 1 - pump, 2 - stop valve, 3 and 4 - pressure transducers, 5 - DN 40 ball valve).

The purpose of the measurements was to identify the behaviour of the pressure differential on the test valve in the function of the flow rate. To that end, the values recorded for each measurement included the water flow rate $(\mathrm{Qv})$, flow velocity $(w)$ and pressure ( $p$ ) both before and after the DN40 valve. The position of the ball was gradually changed during the test in steps of $10^{\circ}$. The flow coefficients $\mathrm{Kv}$ and $\Phi$ were calculated from the values thus measured.

The same measurements were then made with a valve provided with a closing element having an elliptical shape of the flow orifice (Figure 2).

\subsection{Simulation in Ansys_CFX}

Ansys_CFX software was used for the modelling in which a 3D geometry of the examined flow area was gradually created using the accurate recordings of the real system. After that, the computational grid was generated as one of the major in- 
puts bearing on the computation results.

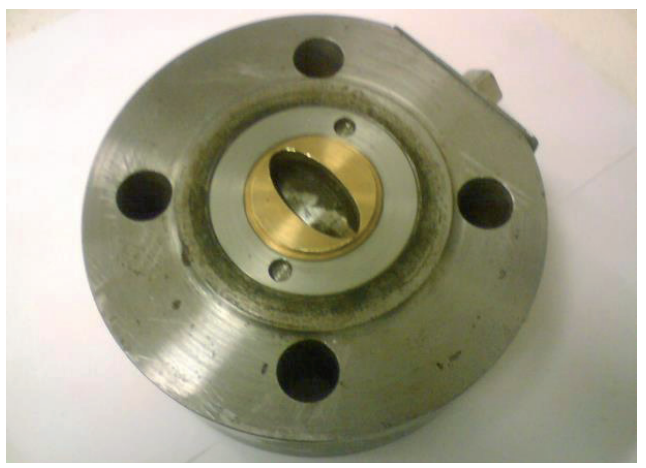

Fig. 2: Ball valve with an elliptical closing element.

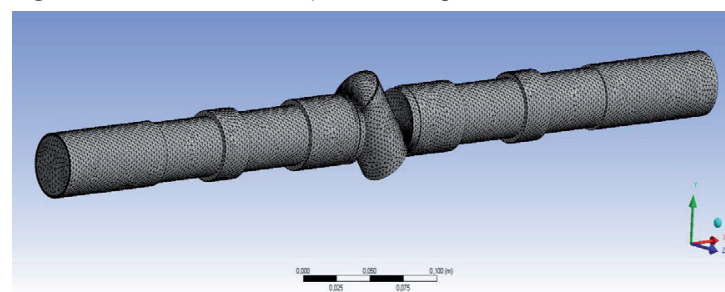

Fig. 3: Computational grid of the piping system with the ball valve.

The next important step was definition of the boundary conditions. In the simulation, the measured flow values were entered as input boundary conditions. The simulation of the flow of the fluid through the ball valve was made with water with the temperature of $17^{\circ} \mathrm{C}$ and pressure of $0.2 \mathrm{MPa}$. The following formula was used in the simulation to calculate the local loss coefficient [2]:

$\zeta=102 \cdot(v \cdot d / v)^{-0,038} \cdot(\cos \delta)^{3,894}$

The above equation describes the behaviour of the local loss coefficient of the ball valve when virtually all relevant values have changed. In the equation, $v$ stands for flow velocity, $d$ for ball valve diameter and $\delta$ for turning angle.

Figure 4 is an illustration of the simulation of flow velocity in the ball valve. The simulation of pressure in the valve with the elliptical closing element is illustrated in Figure 5.

\section{Comparison between the Experimental Mea- surement Results and the Numerical Simulation}

After the numerical simulation, its results were compared against those obtained through the measurements. The graphs below show compari- sons between the ball valve alone and the ball valve with the elliptical closing element.
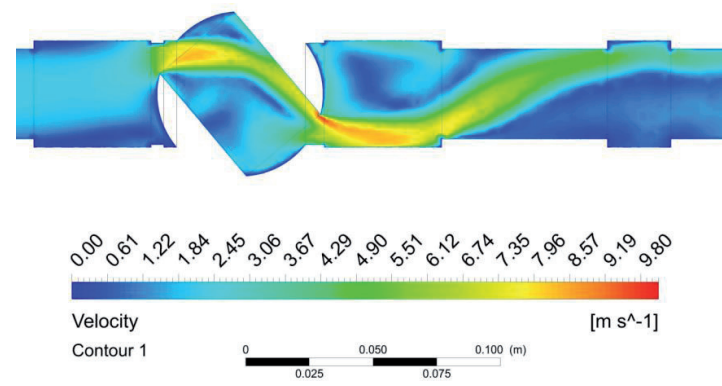

Fig. 4: Flow velocities of the fluid in the ball valve.

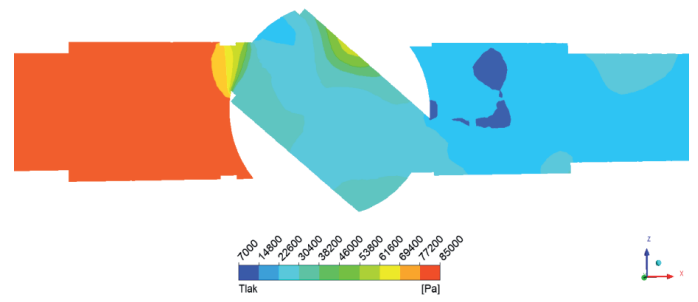

Fig. 5: Pressures acting in the valve with the elliptical closing element.

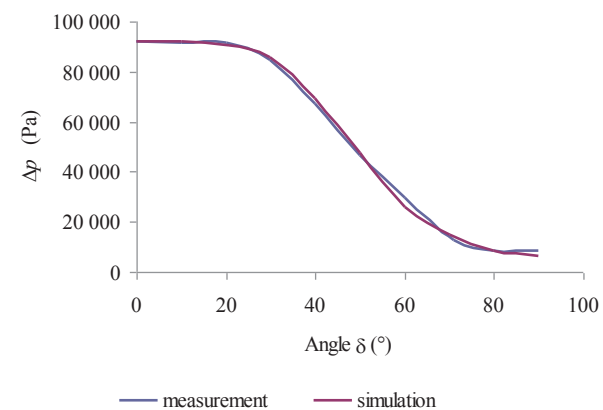

Fig. 6: Comparison of the pressure differential values in function of the turning angle (ö) of the ball valve.

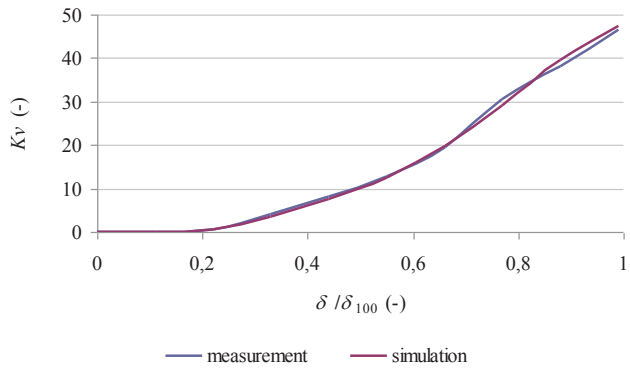

Fig. 7: Comparison of the flow coefficient ( KV) characteristics of the ball valve. 


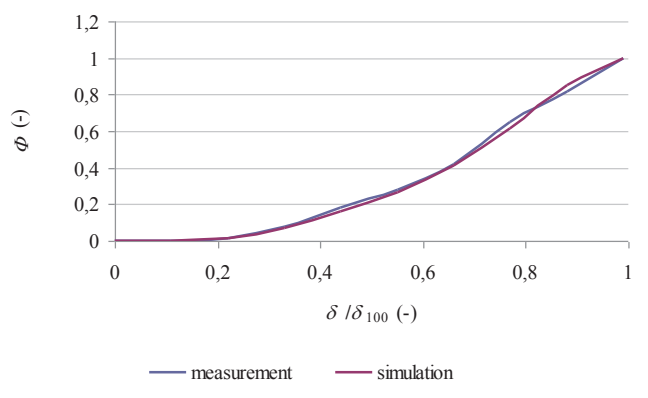

Fig. 8: Comparison of the flow coefficient $(\varphi)$ of the ball valve.

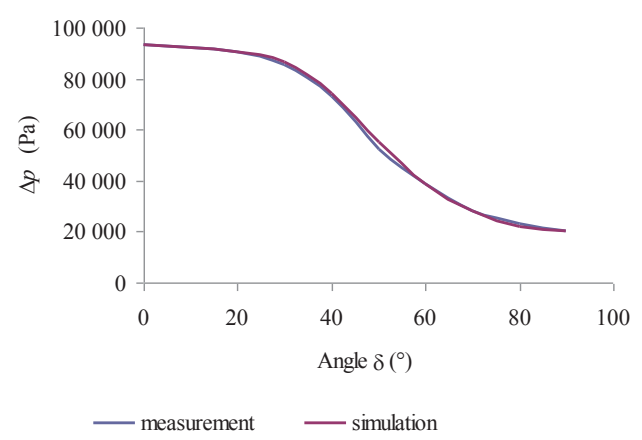

Fig. 9: Comparison of the pressure differential values in the function of the turning angle (ö) of the ball valve with the elliptical closing element.

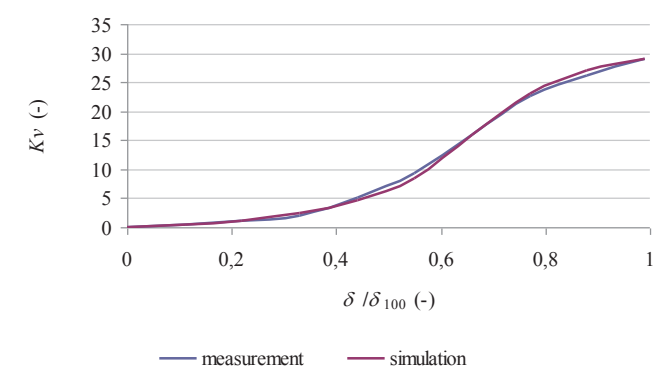

Fig. 10: Comparison of the flow coefficient (Kv) characteristics of the ball valve with the elliptical closing element.

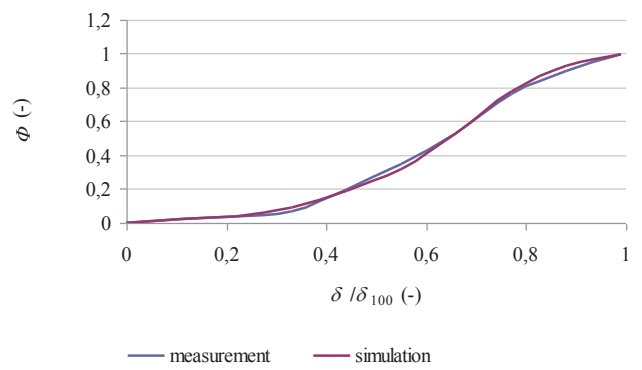

Fig. 11: Comparison of the flow coefficient $(\varphi)$ of the ball valve.
As the relations above indicate, there are only a few variations between the flow rate characteristics arrived at by measuring and those obtained through the simulation. The variations are likely to arise merely from inaccuracies of the measurement with the clamp-on ultrasonic flow meter due to corrosion of the inner surfaces of the piping. The measurement's accuracy might also have been affected by the accuracy of the turning of the ball valve by 100 .

The comparison of characteristics of the ball valves without and with an elliptical closing element further indicates that while ball valves as such are not quite suitable for control applications, if adjusted by provision of flow control slots of various shapes they can be used as flow control devices.

\section{Conclusions}

As this paper presents the results of primary measurements only that were intended to verify the accuracy between the measured and simulated values of the variables observed, measures will be taken after the evaluation to improve the accuracy of both the measurement and numerical simulation results. This will be followed by new measurements and control simulations in Ansys_CFX under precisely defined conditions to determine the characteristics of a prototype valve with other flow control slot shapes.

However, the comparisons of characteristics between the measurements and the simulations have already confirmed the appropriateness of the methodology employed in the process of obtaining the characteristics of the fittings. As already mentioned earlier in this paper, ball valves provided with a flow control slot of a certain shape can be successfully used in flow control applications. Therefore, verification of control properties of a valve with a conically shaped closing element, which has not been examined yet, will be another useful exercise.

\section{Acknowledgments}

The authors would like to express their gratitude to Scientific Grant Agency VEGA MŠ SR for the support of this work under Project No. 1/0686/13.

\section{References}

[1] Roček, J.: Průmyslové armatury. Vydavatel'stvo Informato- 
rium, 2008. 256 s.: ISBN: 859431501206

[2] Brestovič, T. ; Kubík, M. ; Jasminská, N.: Využitie numerických metód v Ansys_CFX na určovanie súčinitelov tlakových strát. Plynár-Vodár-Kúrenár-Klimatizácia, Roč.10, 2/2012, s.30-31. ISSN 1335-9614

[3] Zborník - LDM 2009. [online] 2012. Dostupné na internete: < http://www.ldm.sk/Zbornik/Zbornik-LDM-2009.pdf>

[4] Blejchař, T.: Návody do cvičení "Modelování proudění" - CFX. VŠB TU Ostrava, 2008, s.132

[5] Nekvasil, R., Neterda, Z.: Influence of media mixing rates in T-joints upon their damage. Applied and Computational Mechanics, Vol. 1, No.1, 2007, p.571 - 576. ISSN 1802-680X.

[6] Trebuňa, F.; Šimčák, F.; Bocko, J.; Trebuňa,P.: Failure analysis of mechanical elements in steelworks equipment by methods of experimental mechanics. Eng. Fail. Anal., 17 (4) (2010), p. 787-801

[3] Bigoš, P: Dynamical strenght and durability of machine parts. Acta Mechanica Slovaca. Vol. 10, No. 4-B, Optimalizácia mechanických sústav a zariadení, 2006, p. 61-72. ISSN 1335-2393120

[4] Papučík, Š.; Kapjor, A.; Smatanová, H.; Horváth, Z.; Pilát, P.: Flow field optimalization in the tunnel with oblong fan system from the aspect of energetic severity and fire safety, TRANSCOM 2007, ŽU jún, 25-27, 2007, str. 215; ISBN 978-808070-696-8

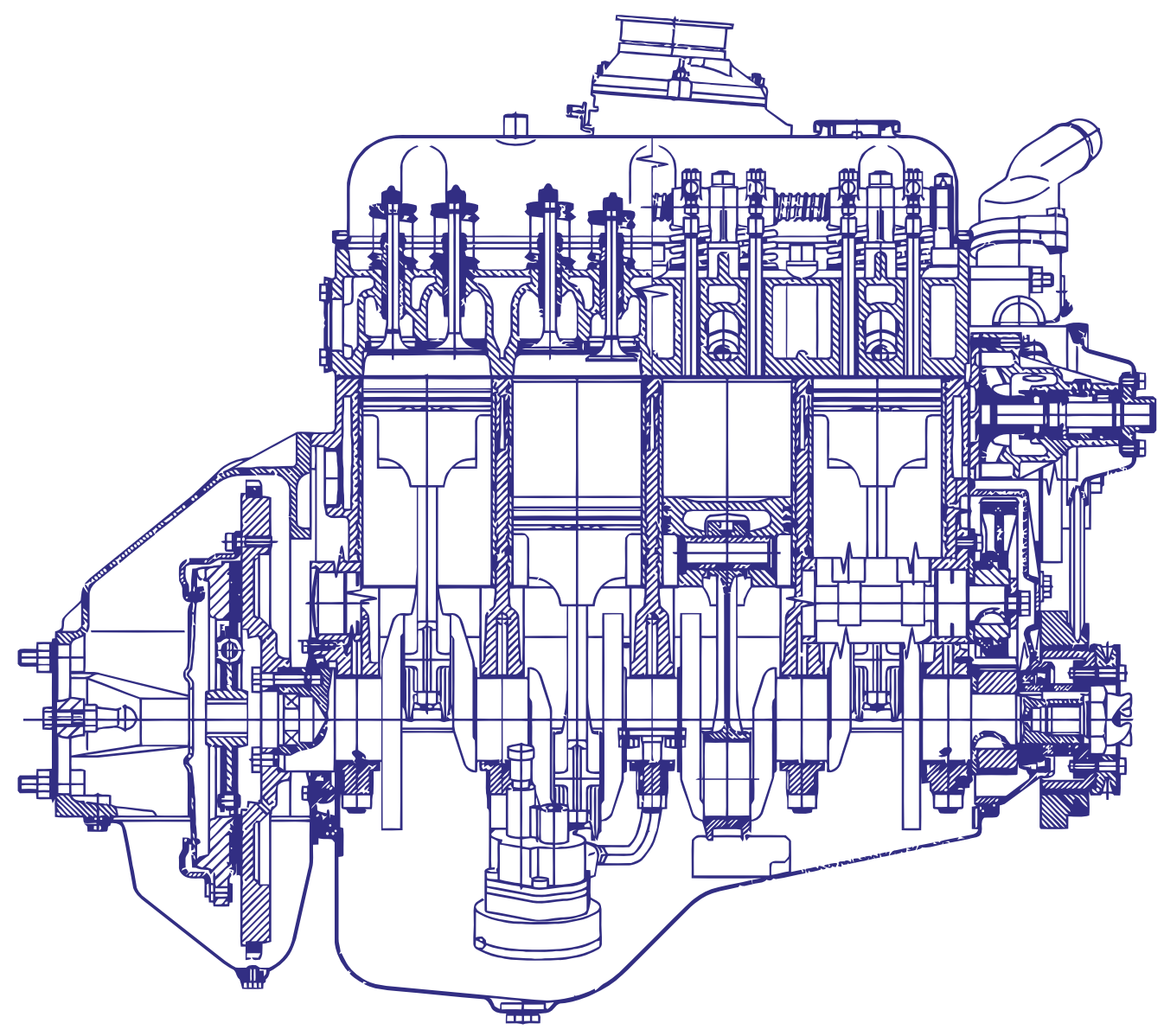

